\title{
Explanation and Prioritization of Required Skills for Teaching in Farhangian University from Authorities and Professors' Point of View ${ }^{1}$
}

\author{
Batool Basiri \\ Head Researcher, PhD Student in Curriculum Development in Neither Isfahan University, \\ Lecturer in Farhangiyan and Payame Noor University (PNU) \\ Email:b_basiry@yahoo.com
}

\author{
Ahmadreza Nasr \\ Professor in Education at the University of Isfahan \\ Email: arnasr@edu.ui.ac.ir
}

\section{Seyedebrahim Mirshahjafari}

Professor in Education at the University of Isfahan Email: jafari@edu.ui.ac.ir

\author{
Mahmood Mehrmohammadi \\ Professor in Education at the University of Tarbiyat Modares \\ Email: mehrmohammadi_tmu@hotmail.com
}

\section{Doi:10.5901/mjss.2016.v7n3s3p221}

\section{Abstract}

The present research mainly aims to identity and prioritize the skills required for teaching in Farhangian University. The research is of applied type, and the method is descriptive-analytical and survey. Qualitative and quantitative methods have been used in order to carry out the research. The statistical population was the qualitative part of all authorities in education throughout the country out of whom 19 were purposefully selected as samples. The statistical population in the quantitative part consisted of 181 academic members and instructors of Farhangian University in 6 provinces in the $4^{\text {th }}$ pole of the country out of whom 150 people were randomly selected. The research data were collected from semi-structured interviews and realized questionnaires. It is worth mentioning that the findings reveal that the results obtained in the quantitative part are in agreement with those obtained in the qualitative part. According to these results, in both parts, the most important pedagogical needs of academic members in teaching skills consist of: 1)Ability to transfer the knowledge and concepts to student teachers, 2) Acquaintance with practical experiences of professors with high quality of teaching, 3) Ability to select teaching methods appropriate to the course subjects and type of class, and 4) Acquaintance with the psychological fundamentals of teaching. Moreover, the findings in this research in the quantitative part showed that the academic members' need for learning 'teaching skills" is more than medium.

Keywords: Educational need, Teaching skills, Academic members, Farhangian University

\section{Introduction and Statement of the Issue}

"Teaching" is said to be an art, but an art superior to that is "training teachers". However, the art of teaching is not spontaneous; rather, the teacher acquires this art through precise planning and experience, which is indicative of his understanding of various teaching techniques (Donald C, translated by Mahjoor, 2000). In fact, the eligibility of an educational system is as much as that of its teachers; and no country can go beyond the level of its teachers. On this basis, teacher training deserves the strongest precise and continual attention (UNESCO, 1990). Mehrmohammadi (1992) is of the opinion that thinking about how to improve teacher training is considered the most important part of the educational system, which should be encouraged among the elite in the society (p., 39).Actually, universities have three

1. This article is extracted from PhD thesis which is conducted under the support of Farhangian University. 
missions; that is, educational, research and services; and no doubt, the educational performance is an introduction and the cornerstone of other performances (Amin Khandaghi \& Seifi, 2013:2). With regard to the fact that the costs of educational systems have so far had an ascending trend in developed countries, if the educational stages including the stage of determining educational needs are not expressed and implemented properly, a loss in educational efficiency will follow (GhasemiPouya, 2000). Hence, with regard to changes, developments and innovations in the present society such as changing Teacher Training Centers to Farhangian University, the need for a planning process for updating the specialized knowledge and skills required by the academic members of this university through needs analysis is an inevitable necessity. However, not much attention has yet been paid to this important issue by researchers. For this reason, the main objective of the present research is to deal with expressing and prioritization of the required skills for teaching in Farhangian University through educational needs analysis since the expansion of professional capabilities of academic members is a pivotal factor in the continuation of optimal educational conditions (Timperlry, Wilson, Barrar \& Fung, 2007). In spite of the claim that the effectiveness of universities depend on the capabilities of their academic members, the feedback indicates that teacher training courses in Iran have not had the required efficiency from educational aspect thus requiring research and re-scheduling. For this reason and towards the materialization of the above-mentioned objectives, enquiries were made in twoaspects of domestic and foreign research related to the issue. A study of the previous research indicates that no research has been conducted in this regard yet; however, regarding needs analysis and teaching methodology, studies have been carried out in other universities, and some of the results will be pointed out later.

For instance, some researchers showed that the first priority for the educational needs of academic members has been the promotion of teaching skills with emphasis on teaching at university level because employing suitable teaching methods leads to delight and joy, increase in students' belief and participation in class management, more reference to other textbooks, increase in learning, and decrease in absence from class (Mohammadzadeh Sharif, 1998; Sabzevari et al, 2006;Farhadian et al, 2008;Fallah, 2009;Asadi et al, 2011). Results obtained by other researchers showed that students who had been taught through class participation enjoyed higher educational progress than those taught traditionally (Hosseini, 2009; Yazdianpour et al, 2009). In Nikneshan and Nasr's views (2010), the reason is that each professor is specialized in a particular part of a course, and using this method helps students improve their learning. Some researchers also showed that the quality of training academic members is different depending of the professors' scientific positions, and that there was a significant difference between their training needs in teaching skills with regard to their scientific position and record of service (Akbari Poorang, 2012; Torkzadeh et al, 2013; Khandaghi and Seifi, 2013). Gholami and Asadi's findings (2013) indicate that from the academic members' point of view, the fundamental issues for effective teaching include communicative skills, awareness of trainee and trainer's characteristics, educational skills and background factors. Mehrmohammadi, too, (2014) has pointed out computer knowledge, intelligence quotient in groups and mastery over English, insight and combining mind, capability in knowledge management, acquaintance with technology, enjoying a seeking mind, tendency to be present in facts, citizenship training, strengthening of common sense power, multicultural skills, belief in individuals up to disturbance to group identity,and self-control among the teachers' required skills in his research.

In this regard, a glance at related foreign research works is also inspiring. For instance, evidences collected by Cannon and Newble (1995 showed that there is a relationship between the professor's approach towards teaching and the quality of learning results in students. Professors who follow their teaching with a student-oriented approach usually consider the aim of teaching helping students understand deeply and changing their comprehension (quoted from Nasr et al, 2006, p.28). from Patrick and Smart's view(1998), effectiveness of academic members' teaching has different dimensions such as 1) respecting students, 2)capability of challenging students and instigating their minds, 3) course organization, 4) enjoying oratorical skills and transferring materials and 5) capability of presenting materials appropriately so that they are understandable in the class.

From Weshan's point of view, too, (1999) effective skills for effective teaching include: 1) specialized or professional knowledge, 2) planning for instruction, 3) implementing instructional strategies, 4) human and resource management, 5) evaluating student learning and 6) professional responsibility. Some researchers, too, have regarded teaching skills as the most important educational need for university professors, and have considered educational courses related to teaching as a necessity for the enhancement and promotion of professors' capability in this regard (Clark et al, 2004; Godfery et al, 2004).In this regard, Borko(2004), too, introduced the characteristics of plans related to the promotion of teachers' professional skills as follows: 1) Concentration on the knowledge related to course topics, 2)Knowing how learners learn course topics, 3) how educational content should be significantly presented.Also, Styskal (2008) showed that there was a difference between the status quo and favorable status of professors in teaching skills; that is, there was a significant difference between the educational needs of professors participating in educational 
courses and those who had not taken part.

Kattakayam's research findings (2010), too, emphasize that effective training to decrease professors' educational needs should include cases such as: 1) persuasion of academic members to study suitable periodicals and specialized magazines, 2) participation in lectures, educational workshops and conferences, 3) using video tapes in the area of teaching skills, 4) effective use of internet, 5) regular self-evaluation of effectiveness of professors' training, 6) regular sharing of academic members' experiences and ideas officially and unofficially.Beuckelaer, Lievens and Bucker (2012) also believe that the existence of a variety of cultural capability in the class leads to academic members' better teaching, and in fact cultural difference and variety is a positive and valuable potential and energy for the promotion of academic members.

Justin (2012) is also of the opinion that "teaching" should itself be regarded as a changing factor; rather than a factor being changed. From his view, there is a directional change in higher education plans, which is moving from teaching-centered to learning centered. Results obtained by Laguador and Dotong (2014), too, showed that the theoretical mastery of academic members include cases such as perception of field, mastery and acquaintance with various teaching approaches, perception of different learning consequences, familiarity with methods of assessment and mastery over teaching methodology.Tandeter et al (2014) also introduced various areas of educational needs of academic members as three 1) teaching and learning, 2) management, executive and communicative skills, and 3) research skills.

In a collection of the total researches mentioned, it is so understood that in order to encounter the many challenges of the third millennium, Fahangian University requires effective academic members with teaching motivation so that they employ various teaching skills suitably, paving the way for dynamism and development in their students (Kumez, 1991, p. 43). Therefore, it is necessary that this university revise its present trend dealing with training, strengthening and promoting the professional merits of its academic members by creating change and innovation. According to Mehrmohammadi (2013), effective teaching is a special objective and the main teaching tool for the academic members of Fahangian University. Hence, theuniversity is expected to pave theway for the materializationof this objective by preparing educational plans (Mehrmohammadi in an interview in 2013). It seems that this can be achieved by paying attention to the educational requirements of professors of this university. Therefore, the need for attention to what was mentioned made the researcher deal withthe identification of requirementsof academic members of Fahangian University in the area of teaching skills towards the materialization of the above-mentioned objectives. Based on this, in this article, special attention has been paid to professors' educational activities in the area of teaching skills.So, the main aim of this research is to express and prioritize the skills required for teaching inFahangian University, which are studied in the form of four research questions as follows:

1. What are the academic members' requirements in "teaching skills"?

2. To what extent do academic members need training in Teaching Skills"?

3. What are the most important requirements of academic members in "Teaching Skills"?

4. Are there any differences among academic members' requirements in "Teaching Skills" with regard to demographic variables?

\section{Research Method}

Table 1: Frequency distribution of the instructors and academic members of the research population

\begin{tabular}{|l|c|c|c|}
\hline \multicolumn{1}{|c|}{ Sex } & female & mail & total \\
\hline Mopulation & 45 & 66 & 111 \\
\hline PhD Academic members & 27 & 43 & 70 \\
\hline total & 72 & 109 & 181 \\
\hline
\end{tabular}

The tests used in this research work consisted of multi-way analysis of variance, factor analysis, and single-variable t with a hypothetical average of three.

\section{Research Findings}

After the transcription of the text of 19 interviews, 168 propositions (codes) were extracted. After the analysis of the content based on the propositions, 107 propositions were obtained in the second stage and 77 propositions in the third 
stage and the main categories were determined. With regard to the importance of the subject in this article, the category of "teaching skills" has been studied. In continuation, the needs related to the intended background are presented in Table (2).

Table 2: The most important educational needs expressed by the interviewees in the area of "teaching skills"

\begin{tabular}{|c|l|}
\hline No. & Components \\
\hline 1 & Ability of transferring knowledge and concepts of curriculum to student teachers \\
\hline 2 & Acquaintance with practical experiences of teachers with high-quality teaching ability through their direct narration or observation \\
\hline 3 & Ability to select a teaching method appropriate to the teaching subject and type of the class \\
\hline 4 & Acquaintance with the bases of psychology of teaching (teaching - learning methods) \\
\hline 5 & Acquaintance with different approaches in teaching (student-centered or teacher-centered methods) \\
\hline 6 & Acquaintance with multi-purpose methods in teaching (active teaching methods, course research) \\
\hline 7 & Acquaintance with the standards and teaching general indexes (power and eloquence of speed, ability to answer questions) \\
\hline 8 & Ability in the application of combined teaching method \\
\hline 9 & Acquaintance with teaching philosophy principles and the philosophy of education \\
\hline 10 & Acquaintance with indexes and teaching standards through clinical observation \\
\hline 11 & Skill in the application of partnership or group teaching method \\
\hline 12 & Acquaintance with the goals of teacher-student syllabus in the area of teaching skills \\
\hline
\end{tabular}

\subsection{First question: What are the educational needs of the academic members in the area of teaching skills?}

From the view of the interviewees, 12 different educational needs contained in Table 2 are the most important needs for the academic members in this area. In continuation a short summary of the selected interviews are presented.

1. Ability of transferring knowledge and curriculum concepts to the teacher- students: skill in transferring knowledge and concepts was confirmed by 14 (73.68\%) interviewees. In fact, the art of transferring knowledge and concepts is one of the most important educational needs for teachers that can be reinforced through training (interviewee 1). From the view of the participants, an academic member of Farhangian University plays two simultaneous roles, i.e. he transfers knowledge and trains teachers. Then, his first role is to educate teachers and then to transfer, modify, and create knowledge (participants 5, 9, and 17). From the view of participant 14, the requisites for a successful teacher at Farhangian University are as follows:

a) "Eloquence" or "Specialized knowledge", i.e. he should know the subject matter he teaches with great control over it.

b) "Procedural knowledge", i.e. having knowledge of teaching methods appropriate to the knowledge and the intended contents

c) "Background knowledge", i.e. the capacity to motivate students to learn and pursue studies.

2. Acquaintance with practical experiences of the teachers with high-quality teaching experience through their direct narration or observation: this educational need was confirmed by 13 participants $(68.42 \%)$ in the interview. Interviewee 18 believed that if teachers who were successful in controlling classes and in teaching expressed their personal experiences in teaching workshops, it would be very useful. Participant 12 believed that the awareness of the teaching methods presented throughout the world, especially in humanities is an educational need for teachers. Also, direct observation of the teaching methods of successful teachers; participation in educational classes held at colleges of humanities or observation of the teaching manner of teachers in developed countries (by direct participation, sabbatical leave, video conference, or even documentary films) can be very helpful in this area.

3. Ability of selecting a teaching method appropriate for the lesson and type of the class: 12 participants $(63.15 \%)$ in the interview recommended this skill. For example, the art of teaching is that the teacher should know what teaching method to follow with regard to the conditions of the class while considering the subject of the lesson. Teachers are usually content with their manner of delivering a speech, which results from their lack of knowledge and skill in the area of teaching (interviewee 6).

4. Acquaintance with the principles of teaching psychology (teaching methods - learning): 11 participants (57.89\%) in the interview confirmed this need. Participant 9 believed that teaching skill requires psychological principles which are in fact the educational psychology proper or learning psychology. The educational psychology helps the instructor to act based on behaviorism approach, cognitivism, or constructivism in his 
teaching. Interviewees 6 and 8 believed that educational psychology was a very applicable and important tool for the teacher to survey the audience during educational process. Additionally, applicability of learning theories, setting educational and teaching goals, preparing lesson plan, and evaluation process are also very applicable.

5. Acquaintance with diverse approaches in teaching (student-centered or teacher-centered approach): this educational need was confirmed by 10 participants (52.63\%). Interviewee 9 believed that a university teacher had to know all the educational approaches and cognition styles and had to be able to use them in his class. For example, he had to be aware that it was not possible to ignore behaviorism approach, since man requires encouragement and attention. But, if only behavior is taken into consideration with no cognitivist view, once again there is no access to the goal. Here, he should know the memory functions, type of memory, cognition hierarchy, and thinking steps; all of these are contained in the cognition approach.

6. Acquaintance with useful methods in teaching (active methods, course scholarship): it is another need that 10 interviewees $(52.63 \%$ ) considered it as a requirement. Interviewee 2 believed that about 20 to 30 percent of the teachers require retraining in this area. Of course, this goal can be attained by teaching to a group of colleagues; teaching in the presence of experienced teachers; and holding teaching competitions as well as holding teaching festivals.

7. Acquiring the standards and general indexes of teaching (power of speech and eloquence, and power of answering questions): 9 interviewees (47.36\%) confirmed the need for skill in the area of teaching and awareness of the standards as well as the general indexes of teaching as the main duties of teachers. Interviewee 11 believed that it was necessary that Farhangian University redefined the standard of the profession of teaching for its teachers and teacher-students. Interviewees 4 and 13 believed that the teaching skills enjoyed some indexes and the most important ones were knowledge, authority, power of speech, eloquence, power of narration, power of creating a sentence, writing, and power of answering the questions asked by the teacher-students.

8. The ability to apply a combined teaching method: this educational need was confirmed by 9 participants (47.36\%). Participant 6 believed that the art of teaching was that the teacher could employ different methods of teaching appropriate to the class conditions and the topic of the lesson. Therefore, the art and skill of teaching are the ability to correctly combine the teaching methods and apply them appropriately. Unfortunately, teachers usually content themselves with lectures and do not enjoy combined teaching methods resulting from their lack of knowledge and skill in this area.

9. Acquaintance with the principles of teaching philosophy and existentialist philosophy of education: knowledge of the philosophy principles of teaching for a teacher is a need taken into consideration by 8 interviewees (42.10\%). Interviewee (9) believed that a teacher had to know about the philosophy of teaching. In other words, he should know three subjects of axiology, epistemology, and ontology in philosophy, i.e. he should know about the view of his students in near future; the type of his teaching and what he expects of them to view the teaching method as a methodology. In fact he should know on what philosophical school his philosophy is based or at least he should specify his approach in teaching. For example, is his philosophical approach in the area of epistemology merely the transfer of knowledge? Does he want the students to produce knowledge and be self-creator? These two views require different philosophical approaches.

10. Acquaintance with indexes and educational standards through clinical observation: this need was confirmed by 7 (36.84\%) interviewees. Interviewee 12 believed that advisors and authorities in teaching should have a chance to observe other teachers' classes and specify the weak and strong points of their teaching method. Unfortunately, we have not had such educational advisors in Farhangian University yet. It is suggested that a powerful group of expert teachers in methodology form a supervising clinic so that teachers can refer to them and bring up their weak points and teaching problems to receive the required guidelines.

11. Skill in the application of partnership or team-working teaching method: seven interviewees (36.84\%) believed that at present, post-modernism teaching methods are spreading throughout the world. There is no doubt that the present changes in different areas of psychology and educational psychology as well as modern educational needs affect the methods of teaching, but unfortunately teachers are not familiar with these changes. In fact, team-working teaching method is not very favored in Farhangian University; it requires special attention.

12. Acquaintance with the goals of the teacher-student syllabus in the area of teaching skills: this need was addressed by 6 (31.57\%) interviewees. Interviewee 16 believed that if it is expected that the teacherstudents acquire competence in teaching area, it is required that the curriculum planners design educational 
programs for this goal. However, since the teachers are the moderators of the schedules, so with no doubt one of the priorities is the training of the teachers and making them acquainted with the goals of the syllabus (Mehrmohammadi, Feb.7, 2004, Tehran: interview).

\subsection{Second question: To what extent do the academic members require training in the area of "teaching skills?}

Table 3: Comparison of the need average rate of academic members to training in the area of "teaching skills" with the hypothetical average of 3

\begin{tabular}{|l|c|c|c|c|c|c|}
\hline component & average & SD & Mean deviation & $\mathrm{t}$ & Degree of freedom & Level of Sig. \\
\hline Need for training & 3.42 & 0.89 & 0.075 & 5.641 & 138 & 0.001 \\
\hline
\end{tabular}

Based on the findings in Table (3), the average of the rate of the needs of the academic members for training in the area of "teaching skills" is 3.42. Since the calculated $t$ is larger than the $t$ in the table, the rate of the need of the academic members for training is more than the average level.

\subsection{Third question: What are the most important needs of the academic members in the area of "teaching skills"?}

Table 4: The most important needs of the academic members in the area of "teaching skills"

\begin{tabular}{|c|c|c|c|c|c|}
\hline & \multicolumn{2}{|l|}{ questions } & & & $\begin{array}{l}\text { Sum of the two } \\
\text { columns } \\
\text { high \& very high }\end{array}$ \\
\hline \multirow{2}{*}{1} & \multirow{2}{*}{$\begin{array}{l}\text { Acquaintance with practical experiences of the teachers with high quality teaching skill } \\
\text { through their direct narration and observation }\end{array}$} & average & SD & Freq. & percentage \\
\hline & & 3.65 & 0.93 & 89 & 59.3 \\
\hline 2 & Capability of preparing different types of lesson plans (daily, semester, yearly) & 3.23 & 1.17 & 78 & 52 \\
\hline 3 & $\begin{array}{l}\text { Selection power of a methodology suitable with the subject of the lesson and type of } \\
\text { class }\end{array}$ & 3.33 & 1.24 & 76 & 50.7 \\
\hline 4 & Acquaintance with the basics of teaching psychology & 3.46 & 1.00 & 76 & 50.7 \\
\hline 5 & $\begin{array}{l}\text { Acquaintance with different approaches in teaching such as student-centered or } \\
\text { teacher-centered approaches }\end{array}$ & 3.42 & 1.13 & 76 & 50.7 \\
\hline 6 & Capability for the transfer of knowledge and concepts to teacher-students & 3.34 & 1.31 & 72 & 48 \\
\hline 7 & Acquaintance with "useful" modern methods in teaching & 3.54 & 1.05 & 71 & 47.3 \\
\hline 8 & Acquaintance with the basics of teaching philosophy & 3.32 & 0.02 & 66 & 44 \\
\hline
\end{tabular}

On the basis of the findings in Table 4, the highest percentage of responses at the levels of 'very high' and 'high' were related to statements (1) with $59.3 \%$ response and then statement (2) with $52 \%$ showing the most important training need for academic members.

\subsection{Fourth question: Is there any difference between the needs of the academic members in the area of teaching} skills with regard to demographic variables?

Table 5: multi-way analysis of variance of scores for the needs of the academic members in the area of teaching skills with regard to demographic variables.

\begin{tabular}{|l|c|c|c|c|c|}
\hline Source & Sum of squares & DF & Mean of squares & F & Level of sig. \\
\hline Sex & 1.661 & 1 & 1.661 & 2.077 & 0.152 \\
\hline Level of education & 0.019 & 1 & 0.019 & 0.023 & 0.879 \\
\hline Work experience & 3.995 & 3 & 1.332 & 1.666 & 0.178 \\
\hline Province of teaching & 3.590 & 3 & 1.197 & 1.297 & 0.219 \\
\hline
\end{tabular}

The results of Table 5 show that there is no significant difference between the scores for the needs of the academic members in the area of teaching skills in terms of demographic variables. 


\section{Discussion and Conclusion}

People have realized that one of the most important and effective infrastructures in the area of development and progress for the country is the improvement of teacher training, but unfortunately the existing evidence is indicative of the fact that the teacher training courses in Iran are not so effective and efficient from the view of training. Some of the researches performed on the rate of the success of these courses in equipping teachers with the necessary teaching capabilities have shown that they have not been as effective as expected. With regard to the fact that the quality of scientific jobs including teaching and research more than anything else depends on the dynamism and capability of the academic members and the university teachers are considered as the key elements for development, therefore paying attention to their educational needs should be a priority in the development plan of the country. Of these priorities, Farhangian University enjoys an especial and specific place, since it bears the serious responsibility for training teachers. Therefore, the main goal of the present research is to study, explain, and prioritize the skills required for teaching in Farhangian University.

Therefore, a glance at the results of the present research work shows that the main educational need has been expressed by a majority of the interviewees by answering the first question of research twelve as shown in Table (2). As an example, the "ability to transfer knowledge and lesson concepts to teacher-students" is a need suggested by 14 interviewees (73.68\%) and has been confirmed. In fact, $73.68 \%$ of the interviewees have favored the ability to transfer knowledge and concepts as the first and the most important skill for teaching. In this regard, also the results of Table 4 in the quantitative section showed that the statement "ability to transfer knowledge and lesson concepts to teacherstudents" with $48 \%$ answers has been a need that the academic members had felt its need for training. This finding is consistent with those obtained by Patrick and Smart (1998) and Wishan (1999). These researchers also propounded that one of the important factors for the effectiveness of the academic members was their enjoyment of speech skill, power of explanation, and ability to present lessons in an appropriate manner so that students can understand it. In addition, "acquaintance with varied approaches in teaching" in Tables (2) and (4) is another educational need proposed by 10 interviewees (52.63\%). Additionally, 50.7\% of the responses were allocated to this statement, the fifth educational need of the academic members, which are consistent with the results obtained by Ganen, Robert, Newbell, and David (1995); Lagordoor and Dotoung (2014). These researchers have emphasized the execution of lesson plans with a comprehensive-centered approach as the basic need for the academic members.

In response to the second question, the results in Table (3) showed that the average rate of the need of the academic members to training in the area of "skill of teaching" was 3.42, which is more the average level indicating that the teachers need training in this area. It is worth mentioning that these findings conform to those of Mohammadzadeh, Sharif (1999); Sabzevari et al. (2006); Farhadyan et al. (2008); Assadi et al, (2011); Akbari, Pourang (2009); Khandaghi and Sayfi (2010); Torkzadeh et al. (2010); Clark et al. (2004); Godfree et al. (2004); Bourco (2004); Stiscal (2008); Gatayam (2010); Lagodoor and Dotong (2014); and Tandeter et al. (2014). The researches performed by these researchers also showed that the enhancement of teaching skills had been the most necessary need for the academic members in the area of teaching and passing the training courses in teaching skills promoted and increased the ability of the university teachers in the area of teaching skills. In fact, effective teaching consists of the use of video tapes, teaching methods, and learning styles to reduce the educational needs of the university teachers. In fact, the results are indicative of the fact that the components of training and teaching of the academic members had been at a low and medium levels and a majority of the university teachers in this area had not received the required training and had not enjoyed enough knowledge.

In response to the third question, the results in Table (4) showed that the statement, "acquaintance with practical experiences of university teachers with high quality teaching experience through their direct narration" with 59.3\% response was a need with the highest percentage of responses given by the academic members, which is their most important training need. This result is in conformity with the research findings of Catayam (2010). He believes that one of the effective factors in reducing the educational needs of the university teachers is the regular sharing of experiences and opinions of the academic members formally and informally; attending lectures, training workshops, and conferences. It is worth mentioning that this training need was confirmed by 13 interviewees $(68.42 \%)$ in the qualitative section. These participants believed that it would be very useful if the university teachers successful in controlling their classes and in teaching express their personal experiences along with different training subjects in training workshops. Additionally, "ability to prepare different types of lesson plans" is another training need, which is in conformity with the results obtained by Asadi, Ataollah et al. (2011). These researchers also confirmed the teaching plan as the selection priority for the educational needs. Also, "the selection power of a methodology suitable with the subject of the lesson and type of class" is a need that 12 interviewees (63.15\%) recommended this skill which is also in conformity with the results in the 
quantitative section; since the results in Table (4) also show that this statement, with $50.7 \%$ response, is the third training need of the academic members and is inconformity with those obtained by Asadi, Ataollah et al. (2011).Also, these researchers confirmed the application of methodology as the selection priority for the needs of the academic members.

In response to the fourth question, the present research results showed that there was no meaningful difference between the scores of the educational needs for the academic members in terms of sex, level of education, work experience, and their province of teaching. Of course, this finding is not in conformity with that of Torkzadeh et al. (2013), since the finding of the above researchers showed that there was a meaningful difference between the educational needs of the academic members in the area of teaching skills with regard to their academic ranking and their work experience.

Now, with regard to what was mentioned above, it can be said that the results of this research work confirm the previous findings related to training and teaching. It therefore seems that the mentioned and identified educational needs are markedly required by the academic members of Farhangian University. Now, the question brought up is the duty of Farhangian University in relation to promotion and its improvement of training efficiency.

Overall, studying the research literature, interview with authorities, and the results obtained from the questionnaires, the researcher concluded that "training" should be considered as a factor bringing about a change and not as a factor affected by change. It is therefore necessary to bring about some changes in the general plan of training programs in higher education. Therefore, Farhangian University should allocate some resources for the growth of professional development programs and empowerment of its academic members. In general, the researches mentioned above, clearly show the necessity for the transition from the current state to the desired state and there is no doubt that the current trend in training workshops requires modification and review. It necessitates that the training issues presented in these workshops be designed, programmed, and executed in accordance with the educational needs expressed by the university teachers. Overall, with regard to what was mentioned, we can reach the general conclusion that planners of educational systems in universities have to present compelling reasons for the codification of programs and their training plans. Therefore, identification and prioritization of educational needs before the selection of any type of solution can contribute to the rate of efficiency and effectiveness of educational programs in universities and of course, access to this goal is obtainable through scientific need assessment by which the effectiveness and efficacy of trainings can be guaranteed. Therefore, Farhangian University should educate teachers by valuation and paying more attention to education-centered approach to improve its educational efficacy and this is accessible with regard to paying attention to identified educational needs and correct planning. In this regard, the following suggestions are presented:

1. Allocation of some sources for the growth of professional development plans for the academic members.

2. Considering the identified educational needs as a base in educational courses.

3. Formation of a supervisory clinic consisting of experienced university teachers with high quality teaching experience to supervise and guide.

4. Modification and review of methodology workshops consistent with identified educational needs.

5. Presentation of some collaborative lessons to improve the teaching manner of the university teachers.

6. Sending the teachers of Farhangian University to the training classes of successful teachers in other universities like internship courses for teacher students so as to combine theoretical studies with direct educational experiences.

\section{References}

Asadi, Ataollah; Taheri, Mahdokht; and Khoshrang, Houssein. (2011). "Educational Needs of Academic Members: Priorities and strategies". Research in Teaching Medical Sciences, Fall and Winter 2011, 3(2), pp. 36 - 42.

Akbari Pourang, Mohammad. (2012). "The Quality of Virtual Teaching for University Teachers on The Basis of Their Syllabus Orientations in Higher Education System and Presentation of An Appropriate Teaching Pattern". PhD dissertation for Curriculum, College of Education and Psychology, Mashhad Firdausi University.

Amin Khandaghi, Maghsoud and Seifi, Gholamali. (2013). "Capabilities and Effective Skills Required for Teaching at Universities". Quarterly, Research and Planning in Higher Education, No. 69, pp. 121 - 147.

Beuckelaer, A. D., Lievens, F. \& Bucker, J. (2012). The role of faculty members' Cross-cultural competencies in their perceived teaching quality: Evidence from Culturally-Diverse Classes in Four European Countries. The Journal of Higher Education. 83 (2), 217-248.

Borko, H. (2004). Professional development and teacher learning: Mapping the terrain. Educational Researcher, 33(8), 3 - 15.

Canen, Robert; Newbell, David. (1995). "A Guide for The Improvement of Teaching in Universities And Higher Education Centers" trans. Nasser, Ahmadreza; Zare, Hussein; and Pakseresht, Mohammadjafar. Esfahan: Esfahan University Publication.

Campbell, A., McNamara, O., \& Gilory, P. (2004). Practitioner research and professional development in education, Paul Chapman Publishing.

Creswell, J. (2007). Qualitative inquiry and research design: Choosing among five approaches, Thousand Oaks: Sage. 
Clark JM, Houston TK, Kolodner K, Branch WT, Levine RB, Kern DE. (2004) Teaching the teachers: National survey of faculty development in departments of medicine of U.S. teaching hospitals. J Gen Intern Med 2004; 19: 205-14.

Creswell, J. \& Plano Clark, V. (2007). Designing and conductingmixed methods research, Thousand Oaks: Sage.

Donandesi, et al. (2000)."Teaching Strategies (Generalities and Teaching Techniques)", trans. Reza Mahjour, Syamak and Ghyasi, Parvin.Shiraz: Sasan publication.

Farhadyan, Fariba; Totonchi, Mina; Genghis, Tahereh; Haghani, Fariba; and OvisGharn, Shahram (2008). Study of The University Teacher's Attitude Towards Skill and Their Training Need for The Methodology of Practical lessons". Journal of Development Steps in Medical Education, (2)5: pp.143 - 147.

Falah, Hamidreza (2009). "The Effect of Traditional Methodology And Participation Methodology on Achievement and Attitude towards Learning Islamic Education for The Students of Pre-university of Tabriz City in The Academic Year of 2008-2009". Azad Islamic University, Tabriz Branch.

GhasemiPooya, Morteza. (2000). "Efficiency Improvement Plans" Ayeneh Journal: No. 12.

Godfrey J, Dennick R, Welsh C. (2004). Training the trainers: do teaching courses develop teaching skills? Med Educ; $38: 844$ - 847.

Gholami, Khalil; Assadi, Mohammad. (2013). "Professional Experience of The University Teachers in Relation with The Phenomenon of Effective Teaching in Higher Education". Theory and Practice in Lesson Planning Journal, 1'st year, No. 2, pp.5 - 26.

Guest, G., Bunce, A., \& Johnson, L. (2006). How many interviews areenough?: An experiment with data saturation and variability, Field Methods, 18, 5982.

Husseini, Zahra (2009). "Collaborative Learning and Critical Thinking"; Quarterly of Iranian Psychologists, (19)5: pp.199 - 208.

Justin, R. (2012). Non satis scire (To know is not enough): the impact of Europe's Bologna process on the development of learning and assessment in the context of a higher education institution in Ireland. PhD thesis, Dublin City University. Identifier: http://doras.dcu.ie/17509/1/J Rami Vol1\%262 postviva.pdf.

kattakayam, jacob john, (2010). powerful staff development approach a potent strategy for professional improvement. University of Kerala, Trivandrum.

Komez, Arthur Right (1991). "Specialized Training for Teachers", trans. Javaherforoushzadeh.Tehran: Roushd.

Laguador,J.M. Dotong,C.(2014). Knowledge versus Practice on the Outcomes-Based Education Implementation of the Engineering Faculty Members in LPU. International Journal of Academic Research in Progressive Education and Development, 3 (1): 63 - 74.

Mason, I. (2002). Linking qualitative and quantitative data analysis, In: A. Bryman \& R. Burgess (Eds.). Analyzing qualitative data, New York: Routledge.

Mehrmohammadi, Mahmoud (2014). "Life Basic Skills in ICT Era”.Lesson Planning Encyclopedia.

Mehrmohammadi, Mahmoud (2013). "Interview in The Area of Educational Needs of Farhangian University Academic Members". Tehran: Farhangian University, March, 9, 2014.

Mehrmohammadi, Mahmoud (1993). "A View to The Manner of Modification And Type of Necessary Modifications in Teacher Training." Education Quarterly, 3, 37-55.

Mohammadzadeh Sharif, Gholamreza (1998). "Study of Educational Needs of Mashhad Ferdowsi University Academic Members". M.A. Thesis in Education, School of Educational Sciences and Psychology, Database for Theses.

Nikneshan, Shaghayegh; Nasser-Esfahani, Ahmmadreza; Mirshahjafari, Ebrahim, and Fatehizadeh, Maryam (2011). "The Rate of The Use of University Teachers from Creative Methodology And Study of Creative Specifications of University Teachers from The View of Exceptional Talents". Quarterly, Educational Studies and Psychology, (11) 2: pp.145-164.

Noy, C. (2008). Sampling knowledge: The hermeneutics of snowballsampling in qualitative research, International Journal of Social Research Methodology, 11 (4), 327344.

Onwuegbuzie, A. J., \& Leech, N. L. (2007). Sampling designs inqualitative research: Making the sampling process more public, The Qualitative Report, 12 (2), 238254.

Plano Clark, V., Creswell, J., O'Neil Green, D., \& Shope, R. (2008). Mixing quantitative and qualitative approaches: An introduction toemergent mixed methods research, In: S. HesseBiber\& P. Leavy. (Eds.). Handbook of emergent methods, New York: The GuilfordPress.

Patrick, J., \& Smart, R. (1998). An empirical evaluation of teacher effectiveness: The emergence of three critical factors. Assessment and Evaluation in Higher Education, 23 (2), 78 - 165.

Sabzevari, Sakyneh et al. (2006). "Explanation and Prioritization of Educational Needs of University Teachers of The Schools of Medicine in Iran". Secretariat Office for Applied Researches, Vice Chancellor of The Ministry of Health, Treatment, and Medical Training.

Sharifiyan, Ferydoon; Mirshahjafari, Syed Abrahim; Sharif, Mostafa; Mossapoor, Nematollah. (2013). "Viewpoint of Lesson Planning Specialists and Graduate Student about The Manner of The Partnership of The students in Lesson Planning", Quarterly, Educational Modern Approaches, $8^{\text {th }}$ year, No. 1, serial No. 17, pp. 47 - 88.

Styskal, Michael S. (2008). An assessment of the educational and training needs of a Marine Naval Academy Graduate. Monterey California. THESIS, Naval Postgraduate School.

Tandeter H, Castel OC, Nave R, Jotkowitz A. (2014). Needs Assessment for Faculty Development Activities. Journal of Family Medicine, 1 (2): 1 - 3.

Timperley, H., Wilson, A., Barrar, H., \& Fung, I. (2007). Teacher professional learning and development: Best evidence synthesis iteration. Wellington, New Zealand: Ministry of Education.

Tourkzadeh, Jafar; NasseriJahromi, Reza; and Rahmani, Hadi. (2013). "Identification And Prioritization of Educational Needs, A 
standard for Teaching Skills of The Academic Members on The Bases of Occupation and Employed Patterns: A Case Study of Shiraz University". Research in Lesson Planning, 10 th year, second period, (11) 38: pp.86-102.

UNESCO. (1999)."Education for Future" Bangkok Conference. Tehran: Research Center of Research and Planning Organization of The Ministry of Education. 1 $1^{\text {st }}$ edition

Weshan, H. A. (1999). A study of effective teaching skills of preservice student teachers as perceived by cooperating teachers and university supervisors in Jordan. (Doctoral dissertation). Ohio University.

Williams, N. (2006). Social research methods. Thousand Oaks: Sage.

Yazdanpour, Neda; Youssefi, Alireza; Haghani, Fariba. (2010). "The Effect of Project and Participation Education on Academic Achievement of Girl Students of Third Grade Experimental Branch of FooladShahr in Statistics And Modeling". Quarterly, 'Knowledge and Research in Education' Azad University, Esfahan, Khorasgan Branch, 22: 85 - 89. 